general bealth the first few days after his arrival, until the morning of the 28 th July, when he became much worse. He ceased to expectorate pus the evening before, his tem perature ran up, his side became dreadfully painful, and he was so weak that he could not rise from his bed, and altogether he was very ill. Under these circumstances I determined to make an effort to evacuate the abscess without further delay. Fortunately I had the aspirator with me. I showed him the needle and explained to him what I proposed to do. He was greatly alarmed, and stoutly objected; bis wife very sensibly reasoned with him to trust himself altogether in my hands; still he would not hear of it. He thought it "a monstrous thing to poke up a fellow's liver in that way." However, I told him firmly but kindly that I should do it, as I considered it most important, and reassured him as to its perfect safety. He consented rather as a matter of necessity, and in much fear and trembling as to the result. After a minute examination of his side, I explored his liver in two places, but failed to find pus. In the evening I found him sitting in the verandah of his quarter looking quite comfortable, and suff $ə$ ring no pain in his side. He told me that the operation had taken away the pain, and given him complete relief. He said: "For a month past $I$ have not been able to straighten myself with the pain in my side, and now I can walk about as straight as an arrow; in fact, $I$ am a different man. You can explore my liver now as of ten as you like." Mrs. R-1 said that she was perfectly astonished to see him walk about with "a firm step, what he had not been able to do for a long time."

On the following day he again began to expectorate pus, which prevented me from searching further for the abscess. He continued to improve, and I saw him on board the P. and O. steamer Peshawur on the 2 nd August, en route to England. I learned from Mrs. R - (who was kind enough to write me news of him from Galle, A den, Suez, Alexandria, and Malta) that he continued to improve, and had no return of the serere pain in his side, and that the liver disease gradually improved. The irritating matter from his liver, however, set up extensive disease of the right lung. $\mathrm{He}$ had an attack of hæroptysis soon after his arrival at home, which recurred at intervals, and carried him off after a few months.

Remarks. - I wish to direct attention to two points in this case. First, the great objection which poor $\mathrm{R}$ - had to have his liver explored; and I have found the same objection to exist in every case to a greater or less extent. There is perhaps no other simple surgical operation to which the "Britisher" has so great an objection-not in consequence of the pain it causes, for it only gives a short sharp pain while the needle is passing through the skin and musclesonce the instrument enters the liver it causes no pain but there is a general though most ungrounded prejudice against the operation, which medical officers should be prepared to meet. Secondly, the almost immediate and permanent relief of the urgent symptoms which followed the operation was very remarkable. I am not at present prepared to give a physiological explanation of the marvellous effect produced by simply puncturing the liver deeply in two places with a needle. When the abscess is found and evacuated, it is easy enough to understand the relief which follows. Perhaps others can throw light on the subject. (To be concluded.)

\section{THE MURIATE OF CALCIUM AS A THERAPEUTIC AGENT.}

BY ROBERT BELL, M.D., F.F.P.S.G.,

SBYSICIAN TO TEE GLASGOW INSTITUTION FOR DISBASES OF WOMEN AND CHILDRBN, ETC.

I TRUST that a sbort time spent in considering the therapentic properties of a salt which has been till quite recently thought of such little value in the treatment of disease that in some works on materia medica it is not even classed as a therapeu ic agent, may be of advantage to the readers of The LANCET. Chloride of calcium is an agent which, $I$ am sure, only requires to be more thoroughly understood to be appreciated as a remedy, and to be valued as a pharmaceu. lival preparation. 'I'hat it has not hituertu encered largely into the prescriptions of medical men in this city may be inferred from the following incident. I wrote a prescription, the principal ingredient of which was the chloride of cal. cium; this was made up at a most respectable dispensing druggist's shop. In a day or two after, the mother of my little patient came to me complaining that her daughter had only been able to take the medicine once or twice, as it produced such obstinate vomiting. What was my horror on finding that chlorinated lime bad been used instead of what was ordered, and a most sickening compound was the result. On my going to the principal of the firm where the mistake had been made, be coolly told me that he knew of no other chloride of calcium than the one be bad used. I mention this incident to show how very rarely this potent remedy has been taken advantage of.

Cbloride of calcium possesses a most wonderful power in controlling, if not actually curing, many forms of tubercular disease. In my experience I have found no remedy on which so much reliance can be placed in tuberculosis as on this salt; more especially, however, this remark applies to the wasting diseases of children. It has been most extensively used by me during the past four years, and with most gratifying results. Having prescribed it in every form of tubercular disease that has come before me during this period, perhaps a short account of my observations on the effect of the drug may not be uninteresting.

In the wasting diseases of childhood, be these tubercular or not, chloride of calcium has proved itself to be, in my experience, a therapeutic agent of inestimable value. The conditions which indicate the probable usefulness of the salt in children are, first of all, a falling off in flesh. The child may take his food heartily enough-nay, his appetite may be better than usual,-yet he becomes more attenuated every day, he is languid, oftimes sleepless, and the pupils are always very much dilated. When sleep does come on, the little patient frequently starts up in a fright, grinds his teeth, and convulsive twitching of the muscular system will of ten be observed-these symptoms being evidently due to a large amount of undigested food in the lower bowel. Ofttimes there is a craving for stimulants, and a most extraordinary liking for potatoes and other articles of diet containing a large amount of starch. If the mother is questioned, the remark will often be made that the child takes his food so well as to make it quite beyond her power to understand how he does not thrive, but, on the contrary, is falling off every day. And it is remarkable to note how rapidly a fat and healthy-looking child will become a mere shadow of his former self when such a train of symptoms are present. When we come to examine the patient, the face may appear to be pretty plump, but the arms and legs are miserably thin, soft, and flabby, while the abdomen is greatly dis tended, having the cutaneous veins very much engorged. The evacuations should always be examined, when it will be observed that they are much greater in quantity than they ought to be, that undigested food can be largely traced in them, and that their fetor is excessive. Such a state of things distinctly points to great defect in the powers of digestion and assimilation. In fact, none of the food appears to have entered the child as nourishment, it having seemed to pass away in a state of putrid fermentation, while the body has been preying on its own tissues. It is in circumstances such as these that the beneficial effects of the muriate of calcium can be appreciated. If a child is brought to me with the symptoms that have just been enumerated, or if any symptoms indicating a want of assimilating power are observed, I immediately insist on the medicine being administered and continued for several weeks. Its powers in arresting such symptoms, in my opinion, are superior to cod-liver oil or iron; and, what is of no little advantage, very young children sonn get to take it quite readily. Of course, when one is prescribing in disease of this kind, it is absolutely necessary to observe strict dietetic rules. In addition to the internal remedies, it will be of immense service if the abdomen of the patient is gently rubbed, night and morning, with olive oil, and afterwards a flannel bandage applied. With reference to diet, I insist upon a large quantity of milk, and the avoidance of starchy food and sweets. 
The history of one or two cases may perhaps be of service as evidence of what has just been said.

J. F- three years of age, was a most miserablelooking object when he came under my observation about four years ago. His legs and arms were most attenuated, and the abdomen was distended to an extraordinary degree; moreover symptoms of ulceration were present at the umbilicus. This gradually increased till, in a very short time, a false anus became established at thia point, from which passed the most fetid and offensive of stools. To such an extent did the evacuations exude from this opening that very little passed through the rectum. An area extending for several inches round the umbilical orifice was excoriated by the acridity of the discharges. This was counteracted by the application of charcoal poultices, and other antiseptic applications. In consequence of the emaciated and exhausted condition of the patient, the slightest movement caused him intense pain. In spite of all these untoward symptoms, the muriate of nalcium worked a cure, for in fifteen months the fistulous opening healed, the child gained in weight and strength, and now he is a strong and apparently healtby boy, not presenting at this time any appearance outwardly of having been in such a precarious state of health three years and a half ago.

Anotber example:of the curative effects of this salt in the wasting diseases of children will suffice, and this time I will relate the history of three children of one family who were considered to be in a dying condition from tabes mesenterica. 'T'wo children of the same family had, previous to my having been called to attend, been cut off by the same disorder. The three children-all boys-to whom I refer, had all the symptoms of tuberculosis, and appeared to be literally dying on their feet. Their ages varied from three to eight years. Within seven months of the com. mencement of the treatment by muriate of calcium, combined with a judicinus diet, the children were plump and healthy-looking. The abdomen in each individual was reduced to a normal size, the stools had become healthy in appearance and quantity, and had lost their offensive stench. In short, the children were cured. It is now eighteen months since they passed from under my care, and I believe they are still enjoying most excellent health.

Before passing from this part of my paper, I think it would be remiss in me were I to omit mentioning the effect of the muriate upnn the children of the Cambridge-street Orphanage for Girls, of which institution I have the medical charge. The majority of these children are in a most pitiable condition when admitted, and in more than half the cases signs of tubercular disease are very apparent. The muriate of lime has been here put to a crucial test, but it bas shown itself to be worthy of the trust reposed in it, for in none of the cases has it proved of no benefit. All the children to whom it has been administered have improved under its use, and the majority of those affected appear to have shaken themselves clear of the disease altogether. These facts appear doubtless very extraordinary, and so they are, but if anyone would like to prove the matter for himself let him visit the Orphanage, which is always open to visitors, and the matron will gladly show the patients who have been under treatment.

In the tub renlar diseases of bones and joints of children the beneficial effects of the muriate of calcium are very marked. I could recount numerous instances of cure effected by this means, but will content myself by mentioning one. A lad about thirteen years of age was brought under my notice some two years ago. At that time there were eight running sores in different parts of his body, each having connexion with diseased bone. A rib was affected, the bones of the forearm, and the metatarsal bones. He was in a most emaciated condition, but under the muriate of lime treatment he rapidly gained flesh. He took the medicine for fifteen months, at the expiration of which time the lad was perfectly well.

In tubercular disease of the cervical glands I know of no remedy which can equal it. Numberless instances of tuberculous cervical glands yielding to its power have passed under my eye, and, indeed, it is in these affections the muriate of calcium most unmistakably displays its therapeutic properties. A single case may be sufficient to show how it acts in such circumstances. A young man came under my care about eighteen months ago. His condition was as follows :-A running sore proceeded from each parotid and the submaxillary glands, and there was enlargement of some of the cervical glands. His left testicle was also very much hypertrophied, and it was the seat of an abscess. I should add that all these abscesses bad been discharging for a period of several months. He was ordered twenty grains of muriate of calcium three times a day after meals, and in a few months the abscesses in the neck bealed, the enlarged glands became reduced in size, the testicle also recovered, and the patient gained rapidly in weight. and now he is in the enjoyment of good health, though I still advise a continuance of the treatment.

I have treated several cases of phthisis pulmonalis by this means and with most gratifying results when the disease was got at in the early stage. In such cases I havo had distinct cures-at least, the disease bas been checked, emaciation has ceased, the cough has disappeartd, and the patients have recovered their healthy appearance. In conjunction with the muriate I have used a spray containing one-fifteenth of a grain of arsenions acid to one dracbm of water thrice a day, and I think with the effect of expediting the cure.

Before concluding, permit me to add that the only case of tubercular peritonitis that has come under my notice during the past four years has yielded completely to this remedy.

It will be seen from the cases that I have cited that the medicine requires to be perseveringly used. Let me urge on my professional brethren to give it a lengthentd trial and not to be discouraged by an apparent failure. Muriate of calcium can do no possible injury to the economy, while in properly selected cases it will be of incalculable service.

\section{ALOPECIA IN CONGENITAL SYPHILIS.}

BY THOMAS BARLOW, M.D., B Sc.,

ASBISTANT-PHYSICIAN TO THE LONDON HOSPITAR AND TO THB CHILDBEM'B HOSPYYAL, GREAT ORMOND-STEEET.

ALOPECIA in acquired syphilis is common enough, but I have been unable to find any reference in books to loss of hair as a sign of the congenital form of the disease. The first case in which $I$ observed this condition was that of a child who at six weeks old had extensive skin and other lesions caused by congenital syphilis. Amongst other results he had considerable desquamation about the forehead and scalp. When this had cleared off his eyebrows became all but bare, and his scalp extensively so. Although his general improvement under mercurial treatment was rapid and complete, yet, even at eleven months, when he was brought for inspection, half his scalp was bare and shiny, and his eyebrows were still thin.

Since noticing the above I have seen several syphilitic children in whom alopecia has occurred, but to a wuach less extent. In some of them all that one could say was, tbat in a given patch the hair was very much thineed; in others the loss of hair has been as marked as in alopecia areata.

What the natural history of alopecia in acquired syphilis is I cannot say, but in the congenital form wany of the cases which I have seen have, like the first mentioned, been preceded by desquamation of the scalp in the region which has subsequently become bare. In some I have failed to ascertain that there had been desquamation. It has often been very slight.

As to the position, I believe the eyebrows are the most conclusive spots. If in a child from two to three months old one or both eyebrows be bare, it ought always to raise the suspicion of congenital syphilis. The cccipital region has, in some cases, been affected, and with it there bas been a moderate enlargement of the occipital glands. A more characteristic situation is the junction of the frontal with the temporal regions.

There are two provisoes to be borne in mird-first, that in rickety children, with much head sweating and muscular weakness, the occiput very often becomes almost hared of hair; and, second, that in a young baby the wavy anterior margin of the hairy scalp presents a bay where the hair is deficient in each fronto-temporal region. Unless, therefure, the alopecia is very marked on one side, or extends (as I 